\title{
Changes in Orexin-A and Neuropeptide Y Expression in the Hypothalamus of Obese and Lean Zucker Diabetic Fatty Rats
}

\author{
Eun Sung PARK ${ }^{1}$, Je Kyung SEONG ${ }^{1}$, Seong Joon $\mathrm{YI}^{2}$, Jin Sang $\mathrm{KIM}^{3)}$, Heungshik S. LEE ${ }^{1)}$, In Se $\mathrm{LEE}^{1)}$ and \\ Yeo Sung $\mathrm{YOON}^{1) *}$ \\ ${ }^{1)}$ Department of Anatomy and Cell Biology, College of Veterinary Medicine and School of Agricultural Biotechnology, Seoul National \\ University, San 56-1, Shilim-dong, Kwanak-gu, Seoul, 151-742, 2) Anatomy, College of Veterinary Medicine, Kyungpook National \\ University, Daegu 702-701 and ${ }^{3)}$ Physical Therapy, College of Rehabilitation, Daegu University, Daegu 705-714, South Korea
}

(Received 24 June 2004/Accepted 10 March 2005)

\begin{abstract}
This study was carried out to investigate the changes of orexin-A (OXA) and neuropeptide Y (NPY) expression in the hypothalamus of the obese and lean Zucker Diabetic Fatty (ZDF) rats which have a missense mutation in the leptin receptor gene. The mean body weights (MBW) between the obese and lean ZDF rats were significantly different at 28 and 70 postnatal days. However, at 14 postnatal day, there was no significant difference in the MBW between the obese and lean ZDF rats in both male and female. The OXA immunoreactivities were not significantly different between the obese and lean ZDF rats in both sexes at 14, 28, and 70 postnatal days, respectively. The NPY immunoreactivity was higher in the obese than in the lean ZDF rats in both male and female at 28 and 70 postnatal days, whereas there was no significant difference between the obese and lean ZDF rats at 14 postnatal day. These results indicate that both OXA and NPY might halt their roles for food intake in the obese phenotype of the male and female ZDF rats in the preweaning period of 14 postnatal day, whereas NPY might play a main role in the obesity of these rats in the weaning period of 28 and 70 postnatal days.

KEY WORDS: lateral hypothalamus, neuropeptide Y, obesity, orexin-A, Zucker Diabetic fatty rat.
\end{abstract}

J. Vet. Med. Sci. 67(7): 639-646, 2005

Obesity has an important genetic basis. Accordingly, genetic mouse or rat mutants, including $d b / d b$ and $o b / o b$ mice and $\mathrm{fa} / \mathrm{fa}$ rats, become strikingly obese. Molecular analysis has shown that the primary genetic defect in these animals relates to either abolished leptin production (ob/ob mice) or impaired leptin receptors $(d b / d b$ mice and $f a / f a$ rats) $[4,7,9,12]$. The Zucker fatty rats $\left(\operatorname{Lepr}^{\mathrm{fa} / \mathrm{fa}}\right)$ are obese model rats that have a missense mutation in the leptin receptor gene [13]. The fa mutation is an amino acid substitution in the extracellular domain of the leptin receptor [5]. All leptin receptor isoforms are affected by this mutation. As a consequence, the number of receptors on the cell surface and their signal transduction efficiency are decreased [14, 22]. Animals homozygous for the lepr ${ }^{\text {fa }}$ mutation are hyperphagic, hyperinsulinemic and hypercorticosteronemic. These animals also have decreased energy expenditure and compromised thermoregulatory thermogenesis [3, 22].

Many studies have been reported on the contents and the distributions of orexins, neuropeptide Y (NPY), preproorexin gene and NPY gene in the brains of these genetically adult obese rats and on the pathophysiological implications of orexins in obesity compared with lean littermates. For example, Yamamoto et al. [20] have reported lower levels of prepro-orexin mRNA in adult male $C 57 B L / 6 \mathrm{~J}, o b / o b$, and $d b / d b$ mice using in situ hybridization and immunohistochemistry, whereas Tritos et al. [18] did not find any difference in these animals. Stricker-Krongrad et al. [15]

\footnotetext{
* Correspondence to: Yoon, Y. S., Department of Anatomy and Cell Biology, College of Veterinary Medicine, Seoul National University, San 56-1, Shilim-dong, Kwanak-gu, Seoul, 151742 , South Korea.
}

reported that orexins were down-regulated in the hypothalamus of $o b / o b$ mice, contrary to the NPY system. Although not in the obese animals, Yamamoto et al. [21] examined developmental changes of orexins and their receptors in the Sprague-Dawley rat hypothalamus from postnatal day 0 to 10 weeks, using in situ hybridization and immunohistochemistry.

However, the difference of orexin-A (OXA)- and NPYimmunoreactivities in the preweaning and weaning times of the obese and lean Zucker Diabetic Fatty (ZDF) rats has not been reported until now. Therefore, the aim of this study is to investigate the changes of OXA- and NPY-immunoreactivities of the obese $(f a / f a)$ and lean $(f a /+$ or $+/+)$ ZDF rats of 14,28 , and 70 postnatal days.

\section{MATERIALS AND METHODS}

Animals: Male and female ZDF $(\mathrm{fa} /+)$ rats were purchased from Genetic Models (Indianapolis, U.S.A.) and mated each other. They were housed in plastic cages in an air-conditioned room $\left(23-25^{\circ} \mathrm{C}\right)$ under a $12 \mathrm{hr}$ light $(07: 00$ 19:00)/12 hr dark (19:00-07:00) cycle with free access to food and water. Purina 5008 rodent diets $(7.5 \%$ fat $)$ were provided as recommended by Genetic Models Co. (U.S.A.) [8]. All procedures were in accordance with the NIH Guidelines for the Care and Use of Laboratory Animals. After genotyping the pups two days before each 14, 28, and 70 postnatal day, each group was divided into male obese and lean, and female obese and lean, with comprising 5 animals, respectively. The male and female obese $(f a / f a)$ and lean $(f a /+$ or $+/+)$ ZDF rats were sacrificed of 14,28 , and 70 post- 
natal days.

Genotyping: Genotype of $f a$ gene herein was determined with the strategy described previously [13]. DNA was isolated from $3 \mathrm{~mm}$ tail snips. The tissue was placed in $0.5 \mathrm{ml}$ of extraction buffer $(100 \mathrm{mM} / l$ Tris- $\mathrm{HCl}, \mathrm{pH} 8.5,5 \mathrm{mM} / l$ EDTA, $0.2 \% \mathrm{SDS}, 200 \mathrm{mM} / l \mathrm{NaCl}$, and $200 \mu \mathrm{g} / \mathrm{m} l$ proteinase $\mathrm{K}$ ) and incubated overnight at $55^{\circ} \mathrm{C}$ in a shaking water bath. After $15 \mathrm{~min}$ centrifuged at $15,500 \mathrm{~g}$, the supernatant was added to $0.5 \mathrm{~m} l$ of ice-cold isopropanol, and the tubes were shaken to form a precipitant. The tubes were centrifuged at $15,500 \mathrm{~g}$ for $3 \mathrm{~min}$, and the supernatant was discarded. The pellets were washed two times with cold $70 \%$ ethanol and air-dried. The DNA was dissolved in $500 \mu l$ of $\mathrm{H}_{2} \mathrm{O}$ at $55^{\circ} \mathrm{C}$ for $1 \mathrm{hr}$, and the concentration was determined spectrophotometrically. Polymerase chain reactions (PCRs) were performed using the Promega PCR Core system I, 100 $n \mathrm{~g}$ of DNA, $14 \mathrm{pM}$ of each primer, and 30 units of Taq enzyme with the following cycling conditions: $92^{\circ} \mathrm{C}$ for 2 min, 49 cycles at $92^{\circ} \mathrm{C}$ for $30 \mathrm{sec}, 65^{\circ} \mathrm{C}$ for $30 \mathrm{sec}, 68^{\circ} \mathrm{C}$ for $3 \mathrm{~min}$, then $5 \mathrm{~min}$ at $68^{\circ} \mathrm{C}$. The amplified product of $1.8 \mathrm{~kb}$ was digested with Msp I (New England Biolabs, Beverly, U.S.A.), generating a $1.1-\mathrm{kb}$ band for the homozygote wild type $(+/+)$, a $1.0-\mathrm{kb}$ band for the homozygotic $f a$ gene $(f a /$ $f a)$, and $1.1-$ and $1.0-\mathrm{kb}$ bands for the heterozygote $(f a /+)$ (Fig. 1).

Immunohistochemistry: Rats were anesthetized with pentobarbital $(50 \mathrm{mg} / \mathrm{kg}$ i.p. $)$ and perfused transcardially with $0.01 \mathrm{M}$ phosphate buffered saline (PBS, $\mathrm{pH}$ 7.4) followed by $300-500 \mathrm{~m} l$ cold $4 \%$ paraformaldehyde in $0.1 \mathrm{M}$ phosphate buffer (PB, pH 7.4). The perfused brains were removed, postfixed overnight in the same fixative, placed in $30 \%$ sucrose in $0.1 \mathrm{M} \mathrm{PB}(\mathrm{pH} 7.4)$ for 2 days, embedded in OCT compound (Sakura, Tokyo, Japan), and then frozen on dry ice. Cryostat sections $(30 \mu \mathrm{m})$ were stained by avidinbiotin-peroxidase method. Tissues were washed in Trisbuffered saline (TBS) containing $0.25 \%$ Triton X-100 (TBS-TX), incubated in $10 \%$ normal goat serum (NGS) in TBS-TX for $30 \mathrm{~min}$, and then incubated with rabbit polyclonal OXA antiserum (1:1,000, Oncogene, Cambridge, U.S.A.) in TBS-TX containing $1 \%$ NGS overnight. The sections were washed three times, incubated with biotinylated goat anti-rabbit IgG for $2 \mathrm{hr}$, washed again, and processed using peroxidase-conjugated streptavidin for $1 \mathrm{hr}$.

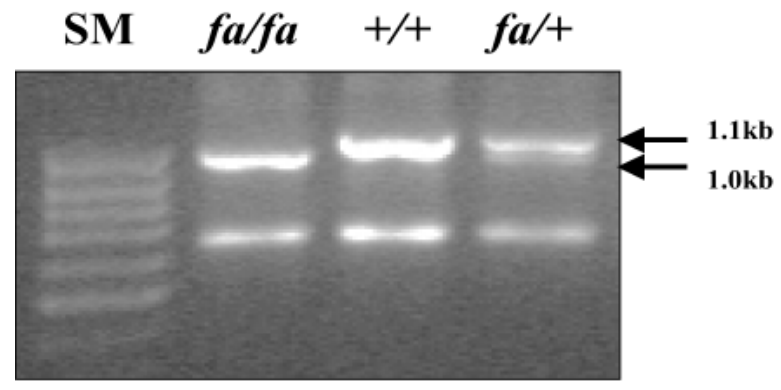

Fig. 1. Genotyping of leptin receptor mutation in ZDF rats by PCR. SM ; size marker.
They were immersed in $0.05 \%$ diaminobenzidine tetrachloride, and $0.05 \% \mathrm{H}_{2} \mathrm{O}_{2}$ in PBS for 2-3 min. Finally, the sections were mounted on gelatin-coated glass slides and examined using on Olympus BX40F4 light microscope (Olympus, Japan). Some sections were incubated with rabbit anti-NPY polyclonal antibody (1:1,000, Chemicon International, Temecula, U.S.A.) and then processed as same procedure as in orexin. The lateral hypothalamus area (LHA) (bregma -2.45 to -2.85) and arcuate nuclei (ARC) in the hypothalamus were identified using the atlas of the rat brain given by Swanson [16]. Six sections per one animal were used for NPY and OXA immunostaining, respectively. The OXA-immunoreactive (IR) neurons were counted in the LHA of the rat brain by two persons, and the NPY immunoreactivity was evaluated as density per unit area $\left(0.01 \mathrm{~mm}^{2}\right)$ in ARC by densitometer.

Statistical analysis: Values are represented as the mean \pm S.E.M. Student's $t$ test was used to determine the statistical differences between the obese and lean groups. A $P$ value under 0.05 was considered as significant.

\section{RESULTS}

Changes of mean body weights $(M B W)$ in the obese and lean ZDF rats: The MBW of the obese and lean ZDF rats at 14 postnatal day were $21.4 \pm 2.4 \mathrm{~g}$ and $20.6 \pm 1.1 \mathrm{~g}$ in the male, and $22.0 \pm 1.7 \mathrm{~g}$ and $25.2 \pm 2.2 \mathrm{~g}$ in the female (Fig. 2). The MBW of the obese and lean ZDF rats at 28 postnatal day were $60.9 \pm 1.1 \mathrm{~g}$ and $55.6 \pm 0.7 \mathrm{~g}$ in the male, and 59.4 $\pm 4.8 \mathrm{~g}$ and $50.7 \pm 1.5 \mathrm{~g}$ in the female (Fig. 2). The MBW of the obese and lean ZDF rats at 70 postnatal day were 300.1 $\pm 4.2 \mathrm{~g}$ and $229.3 \pm 11.9 \mathrm{~g}$ in the male, and $193.5 \pm 4.3 \mathrm{~g}$ and $143.7 \pm 1.9 \mathrm{~g}$ in the female (Fig. 2). That is to say, the MBW were not significantly different between the male and female obese $(f a / f a)$ and lean $(f a /+$ or $+/+)$ ZDF rats, respectively, at 14 postnatal day. However, at 28 and 70 postnatal days, the MBW were significantly different between obese

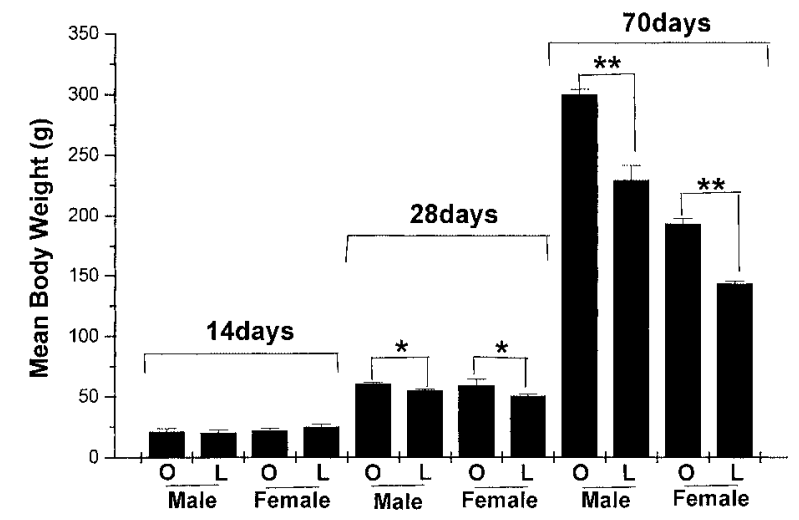

Fig. 2. Comparison of the mean body weights of the obese ( $f a / f a)$ and lean $(f a /+$ or $+/+)$ ZDF rats at 14,28 , and 70 postnatal days. O; Obese, L; Lean. Data were represented as mean \pm S.E.M. $(n=5) .{ }^{*} ; P<0.05, * * ; P<0.01$, compared with the male and female lean ZDF rats, respectively. 


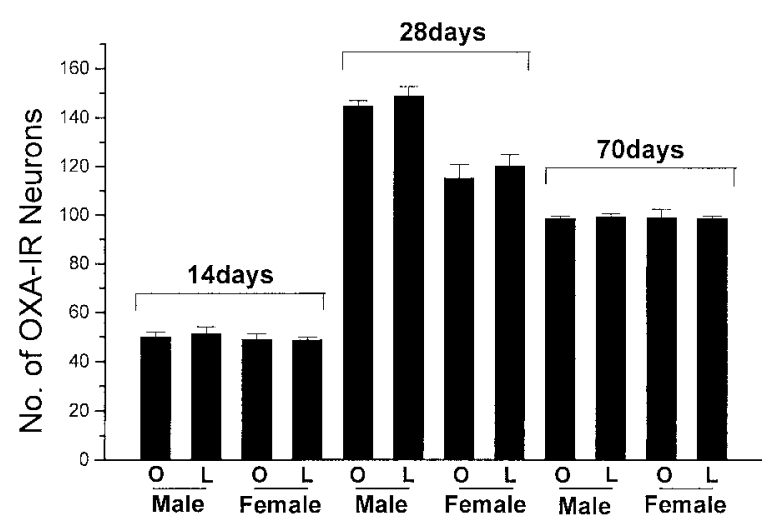

Fig. 3. Comparison of the mean number of the OXA-IR neurons in the LHA (per six sections of one animal ) of the obese and lean ZDF rats at 14,28 , and 70 postnatal days. $P>0.05$.

and lean ZDF male, and obese and lean ZDF female rats, respectively (Fig. 2).

Changes of the OXA-IR neurons in the LHA of the obese and lean $Z D F$ rats at 14,28 , and 70 postnatal days: The OXA-IR neurons were 11 to $25 \mu \mathrm{m}$ in size and multipolar to fusiform in shape, and their dendrites were rarely seen at 14 postnatal day (Fig. 4). The mean numbers of the OXA-IR neurons of the LHA in the obese and lean ZDF rats were $50.2 \pm 1.8$ and $51.4 \pm 2.8$ in the male, and $49.2 \pm 2.2$ and $48.8 \pm 1.2$ in the female, respectively. Statistically, there were no significant differences between the obese and lean ZDF rats in both sexes at 14 postnatal day $(P>0.05$; Fig. 3$)$. At 28 postnatal day, the OXA-IR neurons were 15 to $35 \mu \mathrm{m}$ in size and multipolar to fusiform in shape, and they typically gave rise to two to three dendrites (Fig. 5). The mean numbers of the OXA-IR neurons of the LHA in the obese and lean ZDF rats were $144.8 \pm 2.0$ and $148.8 \pm 3.8$ in the male, and $115.2 \pm 5.6$ and $120.2 \pm 4.6$ in the female, respectively. Statistically, there were no significant differences between the obese and lean ZDF rats in both sexes $(\mathrm{P}>0.05$; Fig. 3). On the other hand, at 70 postnatal day, the OXA-IR neurons were also observed in the LHA. They were 12 to 25 $\mu \mathrm{m}$ in size, and multipolar and round to fusiform in shape, however, their dendrites were more rarely seen than those at 28 postnatal day (Fig. 6). The mean numbers of the OXAIR neurons in the LHA of the obese and lean ZDF rats were $98.5 \pm 1.0$ and $99.3 \pm 1.2$ in the male, and $99.0 \pm 3.3$ and $98.7 \pm 0.9$ in the female, respectively. There were no significant differences between the obese and lean ZDF rats in
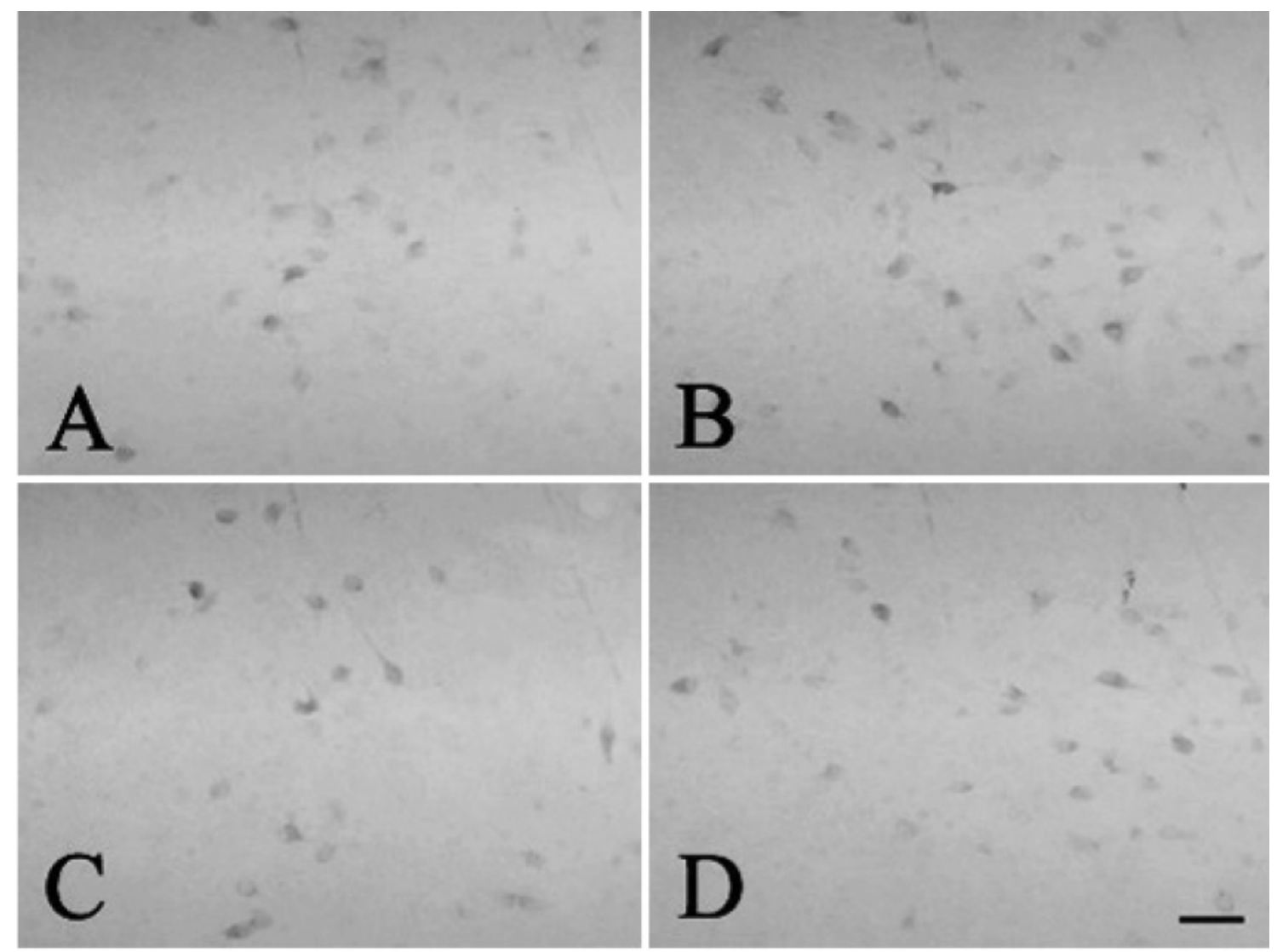

Fig. 4. OXA-IR neurons in the LHA of the obese and lean ZDF rats at 14 postnatal day. A; male obese, B; male lean, C; female obese, and D; female lean. $\mathrm{Bar}=50 \mu \mathrm{m}$. 

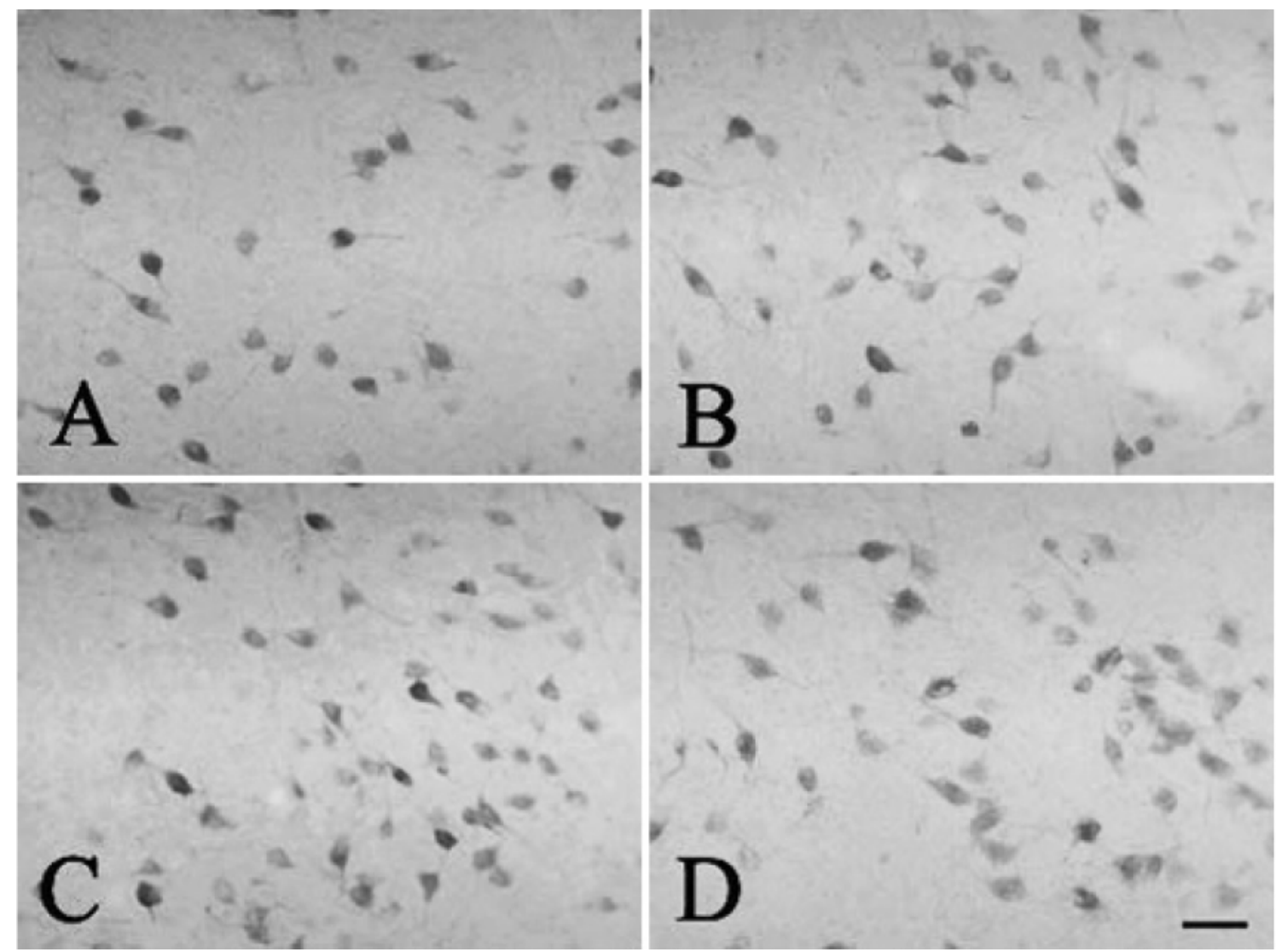

Fig. 5. OXA-IR neurons in the LHA of the obese and lean ZDF rats at 28 postnatal day. A; male obese, B; male lean, C; female obese, and D; female lean. Bar $=50 \mu \mathrm{m}$.

both sexes $(P>0.05$; Fig. 3$)$.

Changes of NPY immunoreactivity in the ARC of the obese and lean $Z D F$ rats at 14, 28, and 70 postnatal days: The NPY-IR neurons were observed, however, the NPY-IR fibers were rarely observed in the ARC. They were about 5 to $10 \mu \mathrm{m}$ in size and mainly oval in shape at 14 postnatal day (Fig. 8). The mean density of NPY immunoreactivity in the ARC of the obese and lean ZDF rats was $128.4 \pm 4.3$ and $127.2 \pm 4.1$ in the male, and $128.3 \pm 3.7$ and $127.5 \pm 3.2$ in the female, respectively. There were no significant differences between the obese and lean ZDF rats in both sexes $(P>0.05$; Fig. 7). At 28 postnatal day, the NPY-IR neurons were observed in the ARC, however, the NPY-IR fibers were rarely observed. They were 5 to $9 \mu \mathrm{m}$ in size and mainly oval in shape (Fig. 9). The mean density of NPY immunoreactivity in the ARC of the obese and lean ZDF rats was $130.0 \pm 0.5$ and $127.3 \pm 1.1$ in the male, and 136.2 \pm 0.7 and $132.3 \pm 1.4$ in the female, respectively. There were significant differences between the obese and lean ZDF rats in both sexes $(P<0.05$; Fig. 7). On the other hand, at 70 postnatal day, the NPY-IR neurons were 5 to $10 \mu \mathrm{m}$ in size and mainly oval in shape in the ARC (Fig. 10). The mean density of NPY immunoreactivity in the ARC of the obese and lean ZDF rats was $120.0 \pm 1.4$ and $95.7 \pm 0.7$ in the male, and $108.2 \pm 1.0$ and $95.1 \pm 0.9$ in the female, respectively. Therefore, there were significant differences between the obese and lean ZDF rats in both sexes $(P<0.05$; Fig. 7).

\section{DISCUSSION}

In this study, OXA immunoreactivity in the hypothalamus of genetically obese rats was compared with that of lean littermates to examine the changes of OXA depending on the postnatal days. Taheri et al. [17] reported that the hypothalamic OXA content was not different between the Zucker rats and the lean controls. Also, the orexin-B (OXB) contents in the lateral hypothalamus of obese Zucker rats did not differ from those of the lean Zucker rats [10]. Absolute quantification of the in situ hybridization signal indicated an $18 \%$ decrease of prepro-orexin mRNA in the $o b / o b$ mice compared to the lean mice. On the other hand, Yamamoto et al. [21] reported that the prepro-orexin mRNA was weakly detected in the LHA from 0 to 15 days after birth, whereas the prepro-orexin mRNA in the LHA markedly increased between days 15 and 20 after birth in SpragueDawley rats. In the present study, there was no significant difference in the number of the OXA-IR neurons in the LHA 

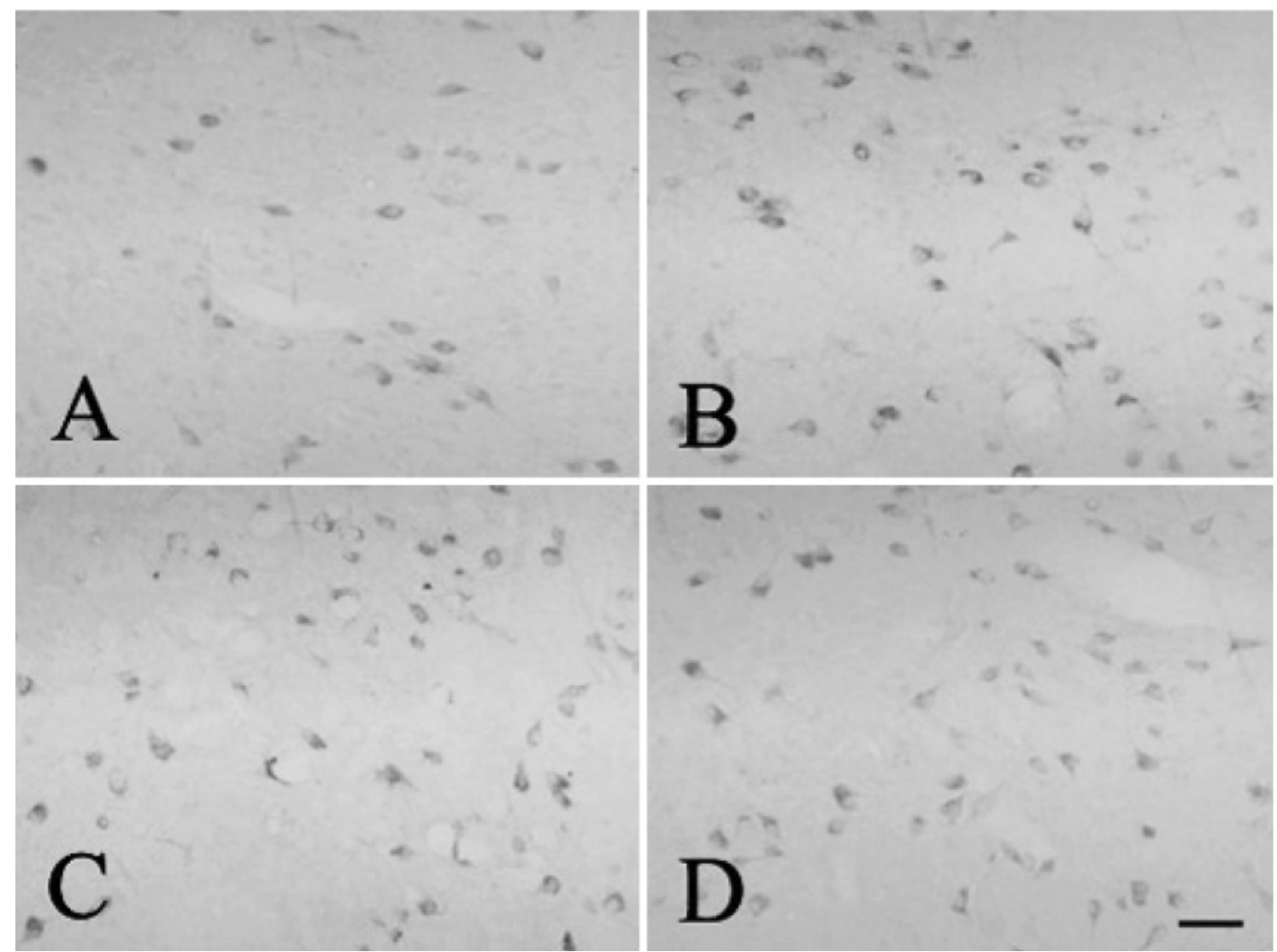

Fig. 6. OXA-IR neurons in the LHA of the obese and lean ZDF rats at 70 postnatal day. A; male obese, B; male lean, C; female obese, and D; female lean. Bar $=50 \mu \mathrm{m}$.

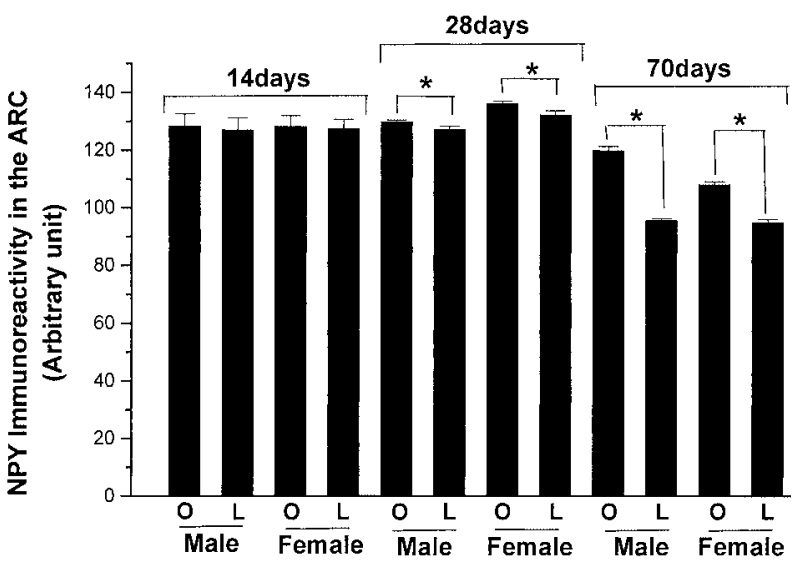

Fig. 7. Comparison of the mean NPY immunoreactivity in the ARC of the obese and lean ZDF rats at 14,28 , and 70 postnatal days. *; $P<0.05$.

between the obese and lean ZDF rats at 14, 28, and 70 postnatal days. Although the OXA neurons in the LHA have been thought to have a stimulating feeding behavior in the mammalian brain, especially, in the rat brain of the previous studies, the fact in our present study that there was no differ- ence in the number of the OXA-IR neurons in the LHA of the brain of the obese and lean ZDF rats at 14, 28, and 70 postnatal days indicated that the OXA is unlikely to be important in the obesity of the ZDF strain rats. However, we need much more study to solve the reason why there was no difference in the number of the OXA-IR neurons in the LHA between the obese and lean ZDF rats at 14, 28, and 70 postnatal days. Nambu et al. [11] reported that orexin immunoreactive neurons in the LHA of the brain of male Wistar rats $(250-350 \mathrm{~g})$ were medium-sized $(30-40 \mu \mathrm{m})$ and multipolar, and they had 2 or 3 primary dendrites. Our present study revealed that there was no difference in the size and shape of the OXA-IR neurons in the LHA between the obese and lean ZDF rats at each postnatal day. However, the size $(15-35 \mu \mathrm{m})$ of the OXA-IR neurons at 28 postnatal day was a little larger than that (11-25 $\mu \mathrm{m}$ and $12-$ $25 \mu \mathrm{m}$, respectively) of the OXA-IR neurons at 14 and 70 postnatal days. Therefore, it is unlikely that the OXA-IR neurons become larger and larger on time dependent.

On the other hand, NPY expression measurement through the same technique showed 2.5-fold increase of NPY expression in the $o b / o b$ mice compared to the lean mice [15]. Erickson et al. [6] reported that, in the absence of NPY, $o b / o b$ mice are less obese because of reduced food 

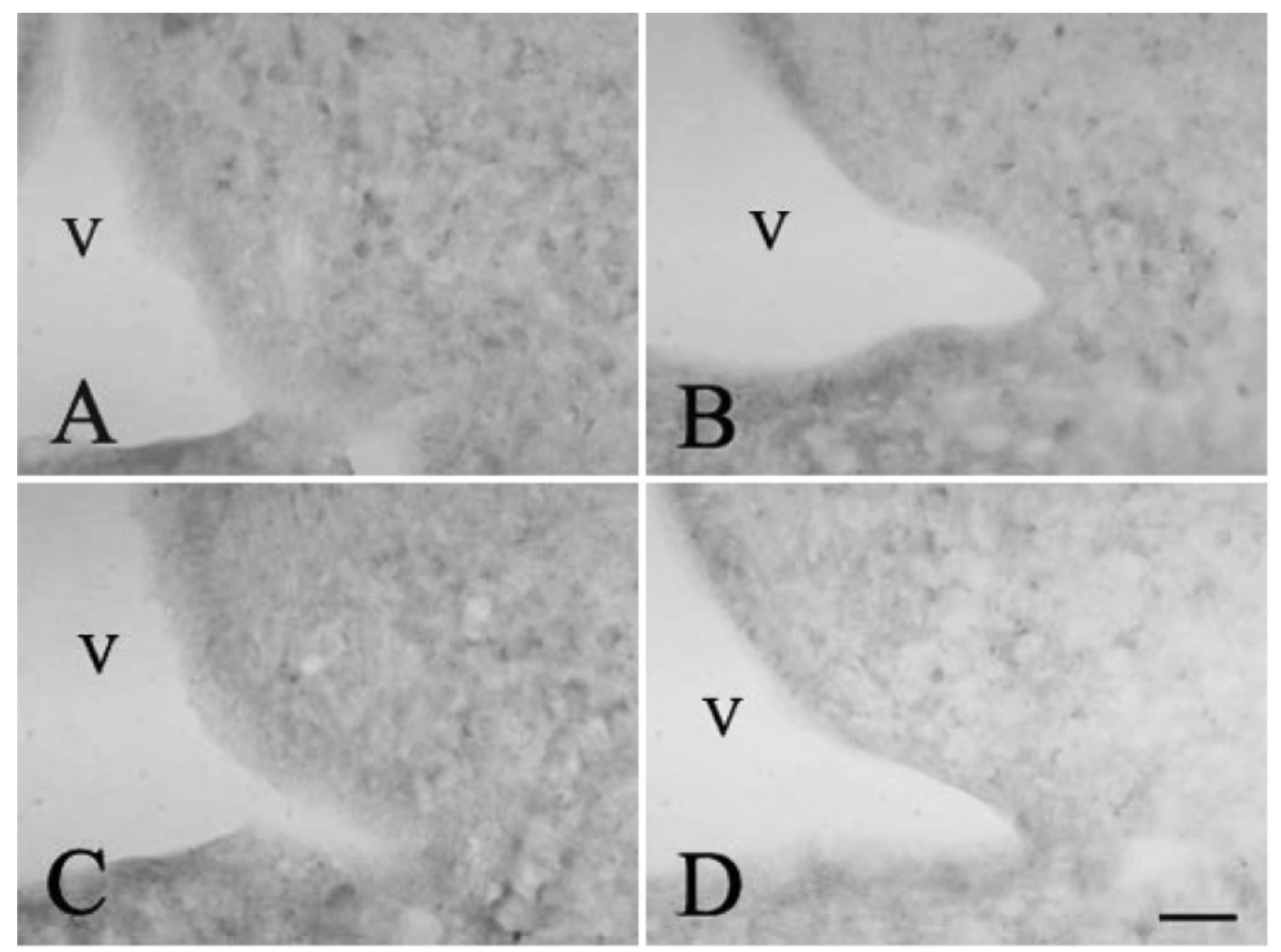

Fig. 8. NPY immunoreactivity in the ARC of the obese and lean ZDF rats at 14 postnatal day. A; male obese, B; male lean, C; female obese, and D; female lean. V; 3rd ventricle. $B a r=30 \mu \mathrm{m}$.

intake and increased energy expenditure. These animals are less severely affected by diabetes, sterility, and somatotropic defects. These results suggest that NPY is a central effector of leptin deficiency. Although the obese ZDF rats have normal leptin, they lack functional leptin receptors. Consequently, the ZDF rats are profoundly hyperphagic, massively obese, hypometabolic, hypothermic, and infertile. In the present experiment, the postnatal 28-day was the first time point at which significant changes in body weight were observed, with final weight being higher in the obese ZDF rats. This finding may result from the more increase of the NPY in the ARC of the obese ZDF rats compared with that of the lean ZDF rats in both sexes. We think that the obese ZDF rats may be always in a kind of condition of starvation from the postnatal 28-day, what is called, from the weaning period. This hypothesis is based on the previous fact that the increased synthesis of NPY in the ARC following food deprivation has been confirmed by the detection of a 2 -fold increase in hypothalamic preproneuropeptide Y mRNA content after an overnight fast and a 4-fold increase after 72 $\mathrm{hr}$ of food deprivation [19]. The previous researchers also reported that in terms of content and expression, the increase of the NPY and NPYmRNA is significant at 30 days after birth when weaned obese $(f a / f a)$ rats begin to overeat $[1,2]$.
In particular, our results revealed that the difference of the NPY immunoreactivity in the ARC between the obese and lean ZDF rats occurred from the postnatal 28-day, what is called, the weaning period to the postnatal 70-day. This finding provide support for the idea that the variation of hypothalamic NPY immunoreactivity in the obese and lean ZDF rats after weaning period may reflect a specific physiological response of feeding regulatory system in the obese ZDF strain rats. However, why does the difference occur in the NPY immunoreactivity in the ARC of the brain of the obese and lean ZDF rats only after weaning period. This reason has to be considered for future investigations.

In summary, there was no significant difference in the change of OXA expression in the obese and lean ZDF rats at 14,28 , and 70 postnatal days, whereas the NPY immunoreactivity was increased in the obese ZDF rats compared with that of the lean ZDF rats after weaning period. These results suggest that after weaning period, the NPY may play a pivotal role in the obesity of the obese ZDF rats compared with the OXA.

ACKNOWLEDGEMENTS. This work was supported by grant No. R01-2000-000-00159-0 from Basic Research Program of the Korea Science and Engineering Foundation 

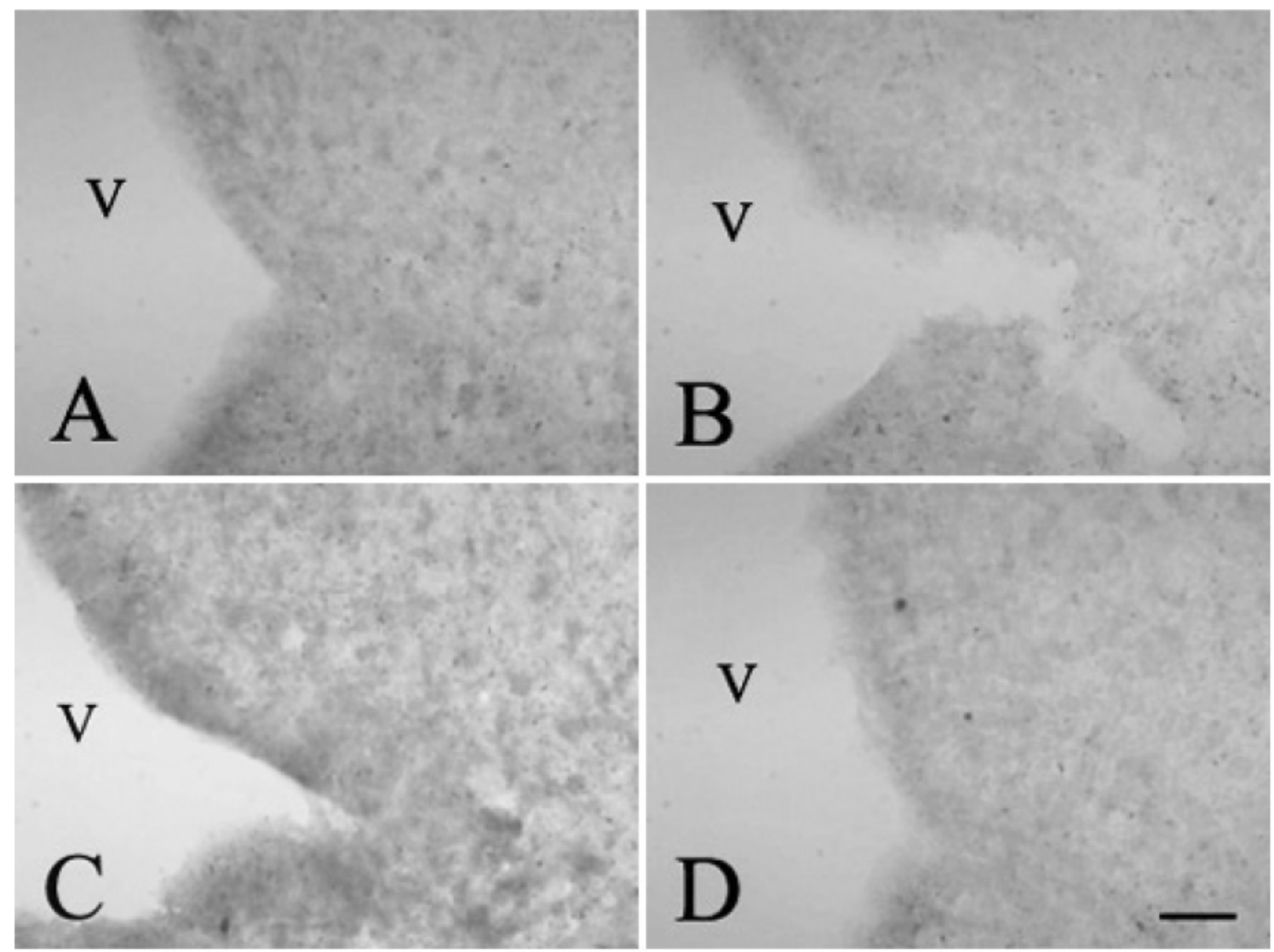

Fig. 9. NPY immunoreactivity in the ARC of the obese and lean ZDF rats at 28 postnatal day. A; male obese, B; male lean, C; female obese, and D; female lean. V; 3rd ventricle. Bar $=30 \mu \mathrm{m}$.

and was also partially supported by Brain Korea 21 program. We are also grateful to Mr. Gwang-Sik Kim for excellent technical assistance.

\section{REFERENCES}

1. Bchini-Hooft van Huijsduijnen, O., Rohner-Jeanrenaud, F. and Jeanrenaud, B. 1993. Hypothalamic neuropeptide Y messenger ribonucleic acid levels in pre-obese and genetically obese $(f a /$ $\mathrm{fa}$ ) rats; potential regulation thereof by corticotropin-releasing factor. J. Neuroendocrinol. 5: 381-386.

2. Beck, B., Burlet, A., Bazin, R., Nicolas, J. -P. and Burlet, C. 1993. Elevated neuropeptide $Y$ in the arcuate nucleus of young obese Zucker rats may contribute to the development of their overeating. J. Nutr. 123: 1168-1172.

3. Bray, G. A., York, D. A. and Fisler, J. S. 1989. Experimental obesity: a homeostatic failure due to defective nutrient stimulation of the sympathetic nervous system. Vitam. Horm. 45: 1125.

4. Campfield, L. A., Smith, F. J., Guisez, Y., Devos, R. and Burn, P. 1995. Recombinant mouse OB protein: evidence for a peripheral signal linking adiposity and central neural networks. Science 269: 546-549.

5. Chua, S. C. Jr., White, D. W., Wu-Peng, X. S., Liu, S. M., Okada, N., Kershaw, E. E., Chung, W. K., Power-Kehoe, L., Chua, M., Tartaglia, L. A. and Leibel, R. L. 1996. Phenotype of fatty due to Gln269Pro mutation in the leptin receptor (Lepr). Diabetes 45: 1141-1143.

6. Erickson, J. C., Hollopeter, G. and Palmiter, R. D. 1996. Attenuation of the obesity syndrome of $o b / o b$ mice by the loss of neuropeptide Y. Science 274: $1704-1707$.

7. Halaas, J. L., Gajiwala, K. S., Maffei, M., Cohen, S. L., Chait, B. T., Rabinowitz, D., Lallone, R. L., Burley, S. K. and Friedman, J. M. 1995. Weight-reducing effects of the plasma protein encoded by the obese gene. Science 269: 543-546.

8. Harmon, J. S., Gleason, C. E., Tanaka, Y., Poitout, V. and Robertson, R. P. 2001. Antecedent hyperglycemia, not hyperlipidemia, is associated with increased islet triacylglycerol content and decreased insulin gene mRNA level in Zucker diabetic fatty rats. Diabetes 50: $2481-2486$.

9. Leibel, R. L., Chung, W. K. and Chua, S. C. Jr. 1997. The molecular genetics of rodent single gene obesities. J. Biol. Chem. 272: 31937-31940.

10. Mondal, M. S., Nakazato, M., Date, Y., Murakami, N., Yanagisawa, M. and Matsukura, S. 1999. Widespread distribution of orexin in rat brain and its regulation upon fasting. Biochem. Biophys. Res. Commun. 256: 495-499.

11. Nambu, T., Sakurai, T., Mizukami, K., Hosoya, Y., Yanagisawa, M. and Goto, K. 1999. Distribution of orexin neurons in the adult rat brain. Brain Res. 827: 243-260.

12. Pelleymounter, M. A., Cullen, M. J., Baker, M. B., Hecht, R., Winters, D., Boone, T. and Collins, F. 1995. Effects of the obese gene product on body weight regulation in $o b / o b$ mice. 

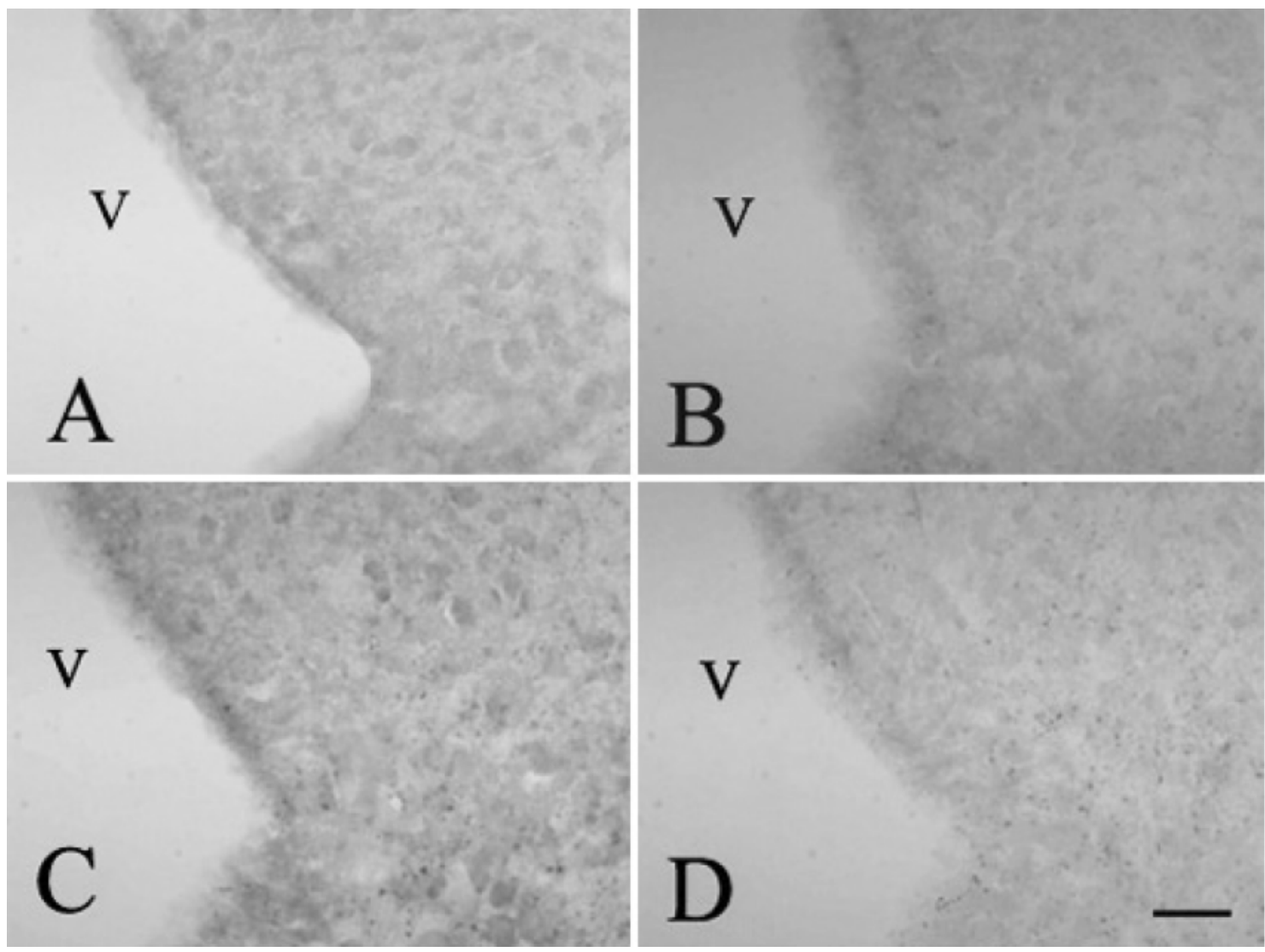

Fig. 10. NPY immunoreactivity in the ARC of the obese and lean ZDF rats at 70 postnatal day. A; male obese, B; male lean, C; female obese, and D; female lean. V; 3rd ventricle. Bar $=30 \mu \mathrm{m}$.

Science 269: $540-543$.

13. Phillips, M. S., Liu, Q., Hammond, H. A., Dugan, V., Hey, P. J., Caskey, C. T. and Hess, J. F. 1996. Leptin receptor missense mutation in the fatty Zucker rat. Nat. Genet. 13: 18-19.

14. Rosenblum, C. I., Tota, M., Cully, D., Smith, T., Collum, R., Qureshi, S., Hess, J. F., Phillips, M. S., Hey, P. J., Vongs, A., Fong, T. M., Xu, L., Chen, H. Y., Smith, R. G., Schindler, C. and Van der Ploeg, L. H. 1996. Functional STAT 1 and 3 signaling by the leptin receptor (OB-R); reduced expression of the rat fatty leptin receptor in transfected cells. Endocrinology 137: 5178-5181.

15. Stricker-Krongrad, A., Richy, S. and Beck, B. 2002. Orexins/ hypocretins in the $o b / o b$ mouse: hypothalamic gene expression, peptide content and metabolic effects. Regul. Pept. 104: $11-20$.

16. Swanson, L. W. 1992. Brain maps: structure of the rat brain, pp. 45-194. In: IV. Atlas of the Rat Brain. Elsevier Science, Amsterdam.

17. Taheri, S., Mahmoodi, M., Opacka-Juffry, J., Ghatei, M. A. and Bloom, S. R. 1999. Distribution and quantification of immunoreactive orexin A in rat tissues. FEBS Lett. 457: 157-
161.

18. Tritos, N. A., Mastaitis, J. W., Kokkotou, E. and Maratos-Flier, E. 2001. Characterization of melanin concentrating hormone and preproorexin expression in the murine hypothalamus. Brain Res. 895: 160-166.

19. White, J. D. and Kershaw, M. 1989. Increased hypothalamic preproneuropeptide Y mRNA content following food deprivation. Soc. Neurosci. 15: 1273 (Abstr.).

20. Yamamoto, Y., Ueta, Y., Date, Y., Nakazato, M., Hara, Y., Serino, R., Nomura, M., Shibuya, I., Matsukura, S. and Yamashita, H. 1999. Down regulation of the prepro-orexin gene expression in genetically obese mice. Mol. Brain Res. 65: 14-22.

21. Yamamoto, Y., Ueta, Y., Hara, Y., Serino, R., Nomura, M., Shibuya, I., Shirahata, A. and Yamashita, H. 2000. Postnatal development of orexin/hypocretin in rats. Mol. Brain Res. 78: 108-119.

22. Yamashita, T., Murakami, T., Iida, M., Kuwajima, M. and Shima, K. 1997. Leptin receptor of Zucker fatty rat performs reduced signal transduction. Diabetes 46: 1077-1080. 